\title{
High prevalence of spondyloarthritis-like MRI lesions in postpartum women: a prospective analysis in relation to maternal, child and birth characteristics
}

Thomas Renson (1) , ${ }^{1,2}$ Anaïs Depicker, ${ }^{1}$ Ann-Sophie De Craemer, ${ }^{1,2}$ Liselotte Deroo, ${ }^{1,2}$ Gaëlle Varkas, ${ }^{1,2}$ Manouk de Hooge (D) ,',2 Philippe Carron (D) , 1,2 Lennart Jans, ${ }^{3}$ Nele Herregods, ${ }^{3}$ Isabelle Dehaene, ${ }^{4}$ Griet Vandenberghe, ${ }^{4}$ Kristien Roelens, ${ }^{4}$ Filip E Van den Bosch, ${ }^{1,2}$ Dirk Elewaut (D) ${ }^{1,2}$

\begin{abstract}
Handling editor Josef $S$ Smolen

- Additional material is published online only. To view please visit the journal online (http://dx.doi.org/10.1136/ annrheumdis-2020-217095)

'Department of Internal Medicine and Pediatrics, Ghent University Hospital, Ghent, Belgium

${ }^{2}$ VIB-UGent Center for Inflammation Research, Ghent University, Ghent, Belgium ${ }^{3}$ Department of Radiology, Ghent University Hospital, Ghent, Belgium

${ }^{4}$ Department of Obstetrics, Ghent University Hospital, Ghent, Belgium
\end{abstract}

Correspondence to Dr Thomas Renson, Department of Internal Medicine and Pediatrics, Ghent University Hospital, 9000 Gent, Belgium; thomas.renson@ugent.be

$T R$ and $A D$ contributed equally.

FEVdB and DE are joint senior authors.

Received 4 February 2020 Revised 25 March 2020 Accepted 3 April 2020

Published Online First 16 April 2020

Check for updates

(c) Author(s) (or their employer(s)) 2020. № commercial re-use. See rights and permissions. Published by BMJ.

To cite: Renson T,

Depicker A, De Craemer A-

$S$, et al. Ann Rheum Dis

2020:79:929-934.

\section{ABSTRACT}

Objectives Bone marrow oedema (BMO) on MRI of sacroiliac joints (SIJS) represents a hallmark of axial spondyloarthritis (SpA), yet such lesions may also occur under augmented mechanical stress in healthy subjects. We therefore sought to delineate the relationship between pregnancy/delivery and pelvic stress through a prospective study with repeated MRI. Results were matched with maternal, child and birth characteristics. Methods Thirty-five women underwent a baseline MRISIJ within the first 10 days after giving birth. MRI was repeated after 6 months and, if positive for sacroiliitis according to the Assessment of SpondyloArthritis International Society (ASAS) definition, after 12 months. $\mathrm{BMO}$ and structural lesions were scored by three trained readers using the Spondyloarthritis Research Consortium of Canada (SPARCC) method.

Results Seventy-seven per cent of the subjects (27/35) displayed sacroiliac BMO immediately postpartum, 60\% fulfilled the ASAS definition of a positive MRI. After 6 months, $46 \%$ of the subjects (15/33) still showed BMO, representing 15\% (5/33) with a positive MRI. After 12 months, MRI was still positive in $12 \%$ of the subjects (4/33). Few structural lesions were detected. Intriguingly, in this study, the presence of BMO was related to a shorter duration of labour and lack of epidural anaesthesia.

Conclusion A surprisingly high prevalence of sacroiliac BMO occurs in women immediately postpartum. Our data reveal a need for a waiting period of at least 6 months to perform an MRI-SIJ in postpartum women with back pain. This study also underscores the importance of interpreting MRI-SIJ findings in the appropriate clinical context.

\section{INTRODUCTION}

Axial spondyloarthritis (axSpA) is an inflammatory rheumatic condition, characterised by involvement of the spine and/or sacroiliac joints (SIJs). Bone marrow oedema (BMO) on MRI of the SIJs plays a central role in the Assessment of SpondyloArthritis International Society (ASAS) classification criteria for axSpA, with a sensitivity of the imaging arm of $66 \% .{ }^{12}$ SIJ BMO on MRI is present in up to $84 \%$ of patients with non-radiographic axSpA. ${ }^{3}$ However, it is frequently seen in a non-inflammatory setting. Recently, a high prevalence of BMO meeting the

\section{Key messages}

What is already known about this subject?

- Bone marrow oedema (BMO) on MRI of the sacroiliac joints (SIJs) lacks specificity for spondyloarthritis and can also occur under circumstances of augmented biomechanical stress.

What does this study add?

- A strikingly high number of postpartum women display sacroiliac BMO on MRI.

- The occurrence of sacroiliac BMO on MRI in postpartum women is associated with a shorter duration of labour and the lack of epidural anaesthesia.

- Sacroiliac BMO on MRI in postpartum women decreases significantly over time, but persists mainly in subjects older than 30 years.

How might this impact on clinical practice or future developments?

- Our data indicate the need for a waiting period of at least 6 months to perform an MRI of the SIJs in postpartum women with back pain.

ASAS definition of a positive MRI for sacroiliitis was seen even in young, active individuals, such as military recruits (36\%) and professional ice hockey players (41\%). ${ }^{45}$ A significant number of healthy volunteers $(23 \%)$ and patients with mechanical chronic back pain $(6 \%-8 \%)$ also fulfil the ASAS definition of a positive MRI for active sacroiliitis. ${ }^{67}$ Seventeen per cent of the mechanical chronic back pain patients show structural SIJ lesions on MRI; however, the different combinations of structural lesions are more seen in patients with axSpA.' Although structural lesions of the SIJ are also important characteristics of axSpA, they are not included in the ASAS MRI definition. ${ }^{8}$ Importantly, structural lesions may differentiate patients with axSpA from patients with a non-SpA back pain.

In contrast to ankylosing spondylitis, nonradiographic axSpA has a more equal sex distribution. ${ }^{9-11}$ Hence, a broad differential diagnosis has to be considered in young women with back pain. Peripartum low back pain is common. In approximately 
$4 \%$ of women, pain persists for more than 6 months postpartum and is occasionally inflammatory in nature. ${ }^{12-17} \mathrm{Up}$ until now, little is known regarding the presence of sacroiliac MRI lesions in postpartum women, which complicates the distinction with axSpA. Sacroiliac BMO during pregnancy and after childbirth has been reported in previous studies, ${ }^{6} 1214$ yet the extent and frequency of MRI lesions is inadequately described and no prospective follow-up was performed. Thus, it can be challenging to discriminate patients with axSpA from postpartum women with persistent back pain. To date, there are no data regarding the evolution of sacroiliac BMO over time in postpartum women, nor links with maternal, child or birth characteristics.

Therefore, our goal was to explore the association between pregnancy and giving birth, and the occurrence of sacroiliac MRI lesions. Furthermore, this study also aimed to detect the time frame in which these lesions disappear. In addition, MRI findings were correlated with maternal, child and birth characteristics.

\section{METHODS}

\section{Subjects}

Thirty-five subjects were recruited from the Department of Obstetrics of the Ghent University Hospital. All subjects provided written informed consent. All included women were between 18 and 45 years old, after an uncomplicated, vaginal childbirth. Exclusion criteria were a known diagnosis of SpA and/or inflammatory bowel disease, severe scoliosis, treatment with anti-tumour necrosis factor- $\alpha$ agents, any kind of contraindication for MRI, childbirth through caesarean section and multiple pregnancy (pregnancy with more than one fetus). Baseline demographic and clinical data (SpA criteria, visual analogue scale (VAS) back pain at night and VAS back pain day and night, duration of labour, gravida/para/abortus status, weight gain during pregnancy, epidural anaesthesia, and sex, weight, length and head circumference of the newborn) were collected. HLAB27 status was determined.

\section{MRI assessment}

Within the first 10 days after giving birth, an MRI-SIJ was performed, which was repeated after 6 months, and, if the second MRI fulfilled the ASAS definition of a positive MRI for sacroiliitis, another MRI-SIJ was performed 12 months after giving birth. Identical settings as in routine clinical practice were adopted. Images were obtained on a 1.5 T MRI unit (Aero/ Avanto, Siemens Medical, Erlangen, Germany). A body flexed array coil was used to scan the SIJs. The sequence protocol included the following: semicoronal (along long axis of the sacral bone) T1-weighted turbo spin echo (tse) (slice thickness (ST): $3 \mathrm{~mm}$; repetition time/echo time (TR/TE): 679/20 ms); semicoronal short tau inversion recovery (STIR) (ST: $3 \mathrm{~mm}$; TR/ TE/TI: 5030/70/150 ms); and axial STIR (ST: $5 \mathrm{~mm}$; TR/TE/TI: 7540/70/150 ms). All images were scored for BMO, capsulitis, enthesitis, high signal intensity in joint space, erosions, sclerosis, fat metaplasia and (partial) ankylosis, as defined by the ASAS MRI working group, by three experienced and calibrated readers $(\mathrm{MdH}, \mathrm{LJ}, \mathrm{NH}) .{ }^{1}$ Scored lesions were regarded by the readers as characteristic for axSpA. Readers were blinded for time sequence and demographic/clinical data. BMO was scored using the Spondyloarthritis Research Consortium of Canada (SPARCC) method, with a maximum score of $72 .{ }^{18} \mathrm{BMO}$ was evaluated for depth (deep lesions=extending $>1 \mathrm{~cm}$ from the articular surface) and intensity (intense lesions=high signal intensity as bright or brighter as vascular structures or intervertebral discs).
Additionally, fulfilment of the ASAS definition of a positive MRI for sacroiliitis ( $\geq 2$ BMO lesions on one slice or $\geq 1$ lesion on two consecutive slices and lesions highly suggestive of $\mathrm{SpA}$ ) was assessed. ${ }^{8}$ Structural lesions (erosions, fatty lesions, sclerosis and ankylosis) were scored using an adjusted SPARCC method. In addition, the proposed cut-off values for erosions and fatty lesions of de Hooge et al were applied for each subject for each time point. ${ }^{19}$ Individual reader scores were combined and for further analyses the median scores were reported. Regarding dichotomous outputs, the consensus of two out of three readers was reported. In case the month $6 \mathrm{MRI}$ fulfilled the ASAS definition of sacroiliitis, the third MRI was provided to the readers for an independent evaluation. A summary of the inter-reader agreement and the measurement error is shown in the online supplementary text.

\section{Statistical analyses and data management}

Statistical analyses were performed using R (V.3.5.2; R Core Team (2018), Vienna, Austria; http://www.R-project.org/) and RStudio (RStudio Team (2018), Boston, Massachusetts, USA; http://www.rstudio.com/). Mean and median values and confidence intervals were determined using descriptive statistics. The significance of SPARCC score differences between time points was calculated by the Wilcoxon signed-rank test. Difference in proportion of subjects having a positive MRI-SIJ was calculated using the McNemar test. Fisher's exact test was used to compare proportions between two independent groups. Correlation with clinical data was assessed using Spearman's rank correlation coefficient. P values $\leq 0.05$ were considered as statistically significant. Non-significant $p$ values were labelled in the main text as NS. Study data were collected and managed using REDCap electronic data capture tools. ${ }^{20} 21$

\section{RESULTS}

\section{Subjects}

Thirty-five subjects were included and underwent the baseline MRI, which was acquired, on average, 5 days postpartum. Thirty-three subjects underwent the month $6 \mathrm{MRI}$, two subjects were lost to follow-up. Demographics and clinical data are displayed in table 1. Eleven subjects (31\%) had back pain at the time of the first MRI. In 8 out of 11 subjects (73\%) back pain was chronic ( $\geq 3$ months) and in four subjects (36\%) back pain was inflammatory according to the ASAS criteria. Two subjects had a positive family history for SpA. No extra-articular SpA manifestations were present, except for three subjects (9\%) with a history of skin psoriasis.

\section{Sacroiliac MRI lesions}

A summary of the detected MRI lesions is presented in table 2. At baseline, the majority of subjects (77\%) displayed BMO on MRISIJ, with a median SPARCC score of 5. BMO was numerically, but not significantly, more prevalent at the iliac compared with the sacral side of the joint ( $14.5 \%$ vs $11.3 \%$ of the quadrants), and significantly more prevalent at the upper SIJ compared with the lower $(15.4 \%$ vs $10.5 \%, \mathrm{p} \leq 0.01)$, and at the anterior part compared with the posterior $(19.6 \%$ vs $6.2 \%, \mathrm{p} \leq 0.001)$. $\mathrm{BMO}$ was equally present at the right SIJ compared with the left (13.7\% vs $12.1 \%)$. Three subjects (9\%) had deep BMO lesions at baseline, whereas seven subjects (20\%) had intense BMO lesions. Twenty-one subjects (60\%) had a positive MRI according to the ASAS definition. High signal intensity in the SIJ space was seen in 13 subjects (37\%); however, median score was low (0). Capsulitis and enthesitis were rarely seen. 


\begin{tabular}{|c|c|}
\hline \multicolumn{2}{|l|}{ Demographics at baseline $(n=35)$} \\
\hline Age, years (mean, SD) & $29.7(2.62)$ \\
\hline Age $>30$ years, $\mathrm{n}(\%)$ & $12(34)$ \\
\hline \multicolumn{2}{|l|}{ Smoking status, n (\%) } \\
\hline Never & $29(83)$ \\
\hline Cessation $>3$ years & $2(6)$ \\
\hline Cessation $<3$ years & $3(9)$ \\
\hline Current smoker & $1(3)$ \\
\hline \multicolumn{2}{|l|}{ Profession, $\mathrm{n}(\%)$} \\
\hline Physical labour & $6(17)$ \\
\hline Non-physical labour & $27(77)$ \\
\hline Unemployed/student & $2(6)$ \\
\hline \multicolumn{2}{|l|}{ Clinical characteristics at baseline $(n=35)$} \\
\hline Weight, kg (mean, SD) & $68(10.9)$ \\
\hline $\mathrm{BMI}, \mathrm{kg} / \mathrm{m}^{2}$ (mean, SD) & $25(3.7)$ \\
\hline Weight gain during pregnancy, $\mathrm{kg}$ (median, $95 \% \mathrm{Cl}$ ) & $10(9$ to 10$)$ \\
\hline HLA-B27 positivity, $n(\%)$ & $1(3)$ \\
\hline Back pain symptoms, n (\%) & $11(31)$ \\
\hline Duration back pain, weeks (mean, SD)* & $13.8(7.65)$ \\
\hline$\geq 3$ months of back pain (=chronic), $n(\%)^{*}$ & $8(73)$ \\
\hline VAS back pain at night (median, $95 \% \mathrm{Cl})^{*}$ & 0.5 (0 to 2$)$ \\
\hline VAS back pain day and night (median, $95 \% \mathrm{Cl})^{*}$ & $1(1$ to 3$)$ \\
\hline Insidious onset of back pain, $\mathrm{n}(\%)^{*}$ & $9(82)$ \\
\hline Back pain improvement with exercise, $n(\%)^{*}$ & $9(82)$ \\
\hline No improvement of back pain with rest, $n(\%)^{*}$ & $3(27)$ \\
\hline Nocturnal back pain, $\mathrm{n}(\%)^{*}$ & $5(46)$ \\
\hline Alternating buttock pain, $\mathrm{n}(\%)^{*}$ & $3(27)$ \\
\hline Morning stiffness, $\mathrm{n}(\%)^{*}$ & $1(9)$ \\
\hline Inflammatory back pain (ASAS criteria), $\mathrm{n}(\%)^{*}$ & $4(36)$ \\
\hline Family history of SpA, n (\%) & $2(6)$ \\
\hline Arthritis (history or current), $\mathrm{n}$ & 0 \\
\hline Enthesitis (history or current), $\mathrm{n}$ & 0 \\
\hline Dactylitis (history or current), $\mathrm{n}$ & 0 \\
\hline Uveitis (history or current), $\mathrm{n}$ & 0 \\
\hline Psoriasis (history or current), $\mathrm{n}(\%)$ & $3(9)$ \\
\hline Inflammatory bowel disease (history or current), $\mathrm{n}$ & 0 \\
\hline \multicolumn{2}{|l|}{ Current pregnancy and delivery $(n=35)$} \\
\hline First pregnancy $(\mathrm{G}=1), \mathrm{n}(\%)$ & $18(51)$ \\
\hline First delivery $(P=1), n(\%)$ & $22(63)$ \\
\hline Duration of labour, hours (median, $95 \% \mathrm{Cl}$ ) & 8 (6 to 12$)$ \\
\hline Epidural anaesthesia, n (\%) & $22(63)$ \\
\hline Male newborn, $\mathrm{n}(\%)$ & $17(49)$ \\
\hline Weight newborn, g (mean, SD) & $3341(502)$ \\
\hline Length newborn, cm (mean, SD) & $50(2.4)$ \\
\hline Head circumference newborn, cm (mean, SD) & $34(1.5)$ \\
\hline
\end{tabular}

${ }^{*}$ Only those patients with back pain were retained.

ASAS, Assessment of SpondyloArthritis international Society; G, gravida; P, para; $\mathrm{SpA}$, spondyloarthritis; VAS, visual analogue scale.

A significant decrease in SPARCC score was seen after 6 months $(p \leq 0.001)$ (figure 1$)$. Five subjects $(15 \%)$ still had a positive MRI ( $\mathrm{p} \leq 0.001)$, persisting in four subjects $(12 \%)$ after 12 months. A significant drop in high signal intensity in the joint space was seen after 6 months $(\mathrm{p} \leq 0.01)$, while no residual capsulitis or enthesitis was reported. There were no deep or intense BMO lesions detected at follow-up.

Almost no structural MRI lesions were seen, neither at baseline nor at follow-up (table 2). No subjects displayed erosions on $\geq 3$ quadrants at baseline, while only one subject showed erosions on three quadrants at month 12 . Two subjects had $\geq 3$ quadrants showing fatty lesions at month 6 and one subject had five quadrants showing fatty lesions at month 12 . In three subjects $(7.4 \%$ of the quadrants) $\mathrm{BMO}$ transformed to fatty lesions during follow-up. An example of a subject with postpartum sacroiliac MRI lesions is shown in figure 2.

\section{Correlation between MRI lesions and clinical data}

The correlation of MRI findings with relevant clinical data is shown in table 3 . No significant association was found between baseline MRI findings and the presence of back pain. Both subjects developing erosions or fatty lesions in $\geq 3$ quadrants after 12 months had back pain. One subject was HLA-B27 positive; she did not have back pain and had a baseline SPARCC score of 8 with one intense BMO lesion. Unfortunately, she was lost to follow-up. Four subjects would have fulfilled the ASAS classification criteria if there was a suspicion of axSpA: three fulfilled the ASAS definition of a positive MRI for sacroiliitis and had inflammatory back pain, one had chronic back pain, a positive MRI and skin psoriasis. Baseline SPARCC scores and a positive MRI-SIJ were not significantly associated with the subject's age, although all five subjects with persistent BMO up to 12 months were older than 30 years. No significant association was found between baseline MRI lesions and the subject's gravidity and parity. A shorter duration of labour was associated with higher baseline SPARCC scores and consequently also with a higher percentage of women fulfilling the ASAS definition of a positive MRI for sacroiliitis at baseline. When epidural anaesthesia was performed, significantly lower baseline SPARCC scores were found. Baseline MRI findings were not associated with the sex and biometry of the newborn.

\section{Other aberrant MRI findings}

In 21 subjects (60\%), aberrant MRI findings, other than sacroiliac inflammatory or structural lesions, were seen at baseline. Fifteen subjects (43\%) had both sacroiliac lesions and other aberrant MRI findings. The most frequent unforeseen MRI finding was symphysis pubis BMO, which was present in 18 subjects $(51 \%)$ at baseline and persisted in 7 (39\%) women after 6 months. Fourteen out of 18 subjects (82\%) with symphysis pubis BMO at baseline also had sacroiliac BMO. Degenerative disc disease was seen in one subject $(3 \%)$ at baseline. Two subjects $(6 \%)$ had a sacral fracture on baseline MRI (figure 3). Both fractures were asymptomatic and healed spontaneously after 6 months.

\section{DISCUSSION}

This is the first prospective study investigating the evolution of sacroiliac MRI lesions in postpartum women. In addition, the correlation of MRI findings with clinical data of mother and child was assessed, which has never been done before. A high prevalence of BMO was seen on MRI-SIJ performed immediately after giving birth, even in subjects without back pain. Notably, a significant portion had a positive MRI for sacroiliitis according to the ASAS definition. Four subjects even fulfilled the ASAS classification criteria for axSpA. A significant decrease in $\mathrm{BMO}$ was seen over time, but persisted mainly in subjects older than 30 years. Interestingly, the presence of BMO was related to a shorter labour and the lack of epidural anaesthesia.

Since pregnancy-related low back pain in women is common ${ }^{22}$ and they occasionally develop an inflammatory pain pattern, our findings affirm concern about the risk of overdiagnosis of axSpA solely based on MRI findings. Although the BMO lesions do not necessarily occur in SIJ locations most specific for SpA, ${ }^{42}$ most 
Table 2 Inflammatory and structural sacroiliac MRI lesions at baseline, after 6 months and after 12 months

\begin{tabular}{|c|c|c|c|c|c|c|c|c|c|}
\hline \multirow[b]{2}{*}{ Inflammatory lesions } & \multicolumn{3}{|l|}{ Baseline $(n=35)$} & \multicolumn{3}{|l|}{ Month $6(n=33)$} & \multicolumn{3}{|l|}{ Month $12(n=5)$} \\
\hline & $\begin{array}{l}\text { Subjects with } \\
\geq 1 \text { lesion } \\
(\mathrm{n}, \%)\end{array}$ & $\begin{array}{l}\text { Range } \\
\text { (min-max) }\end{array}$ & $\begin{array}{l}\text { Median } \\
(95 \% \mathrm{Cl})\end{array}$ & $\begin{array}{l}\text { Subjects with } \\
\geq 1 \text { lesion } \\
(\mathrm{n}, \%)\end{array}$ & $\begin{array}{l}\text { Range } \\
\text { (min-max) }\end{array}$ & $\begin{array}{l}\text { Median } \\
(95 \% \mathrm{CI})\end{array}$ & $\begin{array}{l}\text { Subjects with } \\
\geq 1 \text { lesion } \\
(n, \%)\end{array}$ & $\begin{array}{l}\text { Range } \\
\text { (min-max) }\end{array}$ & $\begin{array}{l}\text { Median } \\
(95 \% \mathrm{CI})\end{array}$ \\
\hline $\begin{array}{l}\text { Sacroiliitis (ASAS } \\
\text { definition) }\end{array}$ & $21(60)$ & - & - & $5(15)$ & - & - & $4(80)$ & - & - \\
\hline SPARCC score & $27(77)$ & $0-30$ & 5 (1 to 8$)$ & $15(46)$ & $0-16$ & 0 (0 to 1$)$ & $4(80)$ & $0-14$ & $4(0$ to 4$)$ \\
\hline Capsulitis & $4(11)$ & $0-12$ & $0(0$ to 0$)$ & 0 & $0-0$ & $0(0$ to 0$)$ & 0 & $0-0$ & $0(0$ to 0$)$ \\
\hline Enthesitis & $1(3)$ & $0-2$ & $0(0$ to 0$)$ & 0 & $0-0$ & 0 (0 to 0$)$ & 0 & $0-0$ & $0(0$ to 0$)$ \\
\hline $\begin{array}{l}\text { High signal intensity joint } \\
\text { space }\end{array}$ & $13(37)$ & $0-12$ & $0(0$ to 1$)$ & $4(12)$ & $0-10$ & $0(0$ to 0$)$ & 0 & $0-0$ & $0(0$ to 0$)$ \\
\hline \multicolumn{10}{|l|}{ Structural lesions } \\
\hline Sclerosis & $4(11)$ & $0-13$ & $0(0$ to 0$)$ & $4(12)$ & $0-10$ & $0(0$ to 0$)$ & $3(60)$ & $0-13$ & $1(0$ to 6$)$ \\
\hline Erosions & $1(3)$ & $0-1$ & $0(0$ to 0$)$ & $2(6)$ & $0-2$ & $0(0$ to 0$)$ & $1(20)$ & $0-3$ & 0 (0 to 3$)$ \\
\hline Fatty lesions & 0 & $0-1$ & $0(0$ to 0$)$ & $5(15)$ & $0-10$ & $0(0$ to 0$)$ & $1(20)$ & $0-5$ & $0(0$ to 5$)$ \\
\hline (Partial) ankylosis & 0 & $0-0$ & $0(0$ to 0$)$ & 0 & $0-0$ & $0(0$ to 0$)$ & 0 & $0-0$ & $0(0$ to 0$)$ \\
\hline
\end{tabular}

ASAS, Assessment of SpondyloArthritis International Society; SPARCC, Spondyloarthritis Research Consortium of Canada.

rheumatologists and radiologists would score these lesions as suggestive for sacroiliitis. This assumption is supported by the findings of Agten et al, showing that BMO on MRI-SIJ of postpartum women is indistinguishable from SpA-related sacroiliitis regarding the extent and distribution of the lesions. ${ }^{12}$ In addition, the median SPARCC score in our study is relatively high considering the mean SPARCC score of 4.9 in the total study population of the ABILITY-1 trial and a median score of 10.2 in a study by Varkas et al in newly diagnosed patients with axSpA warranting treatment. ${ }^{2425}$ Recently, several studies highlighted that BMO lacks specificity for axSpA. Hence, fulfilment of the ASAS definition of a positive MRI for sacroiliitis can also be seen in a non-SpA context, such as in recreational runners, professional ice hockey players, military recruits, chronic back pain patients and healthy controls. ${ }^{4-6}$ In a study by Seven $e t$ al, sacroiliitis on MRI was seen in $41.3 \%$ and $21.4 \%$ of the postpartum women with and without back pain, respectively. ${ }^{26}$ Other recent studies also demonstrated a relatively high presence of sacroiliac $\mathrm{BMO}$ in pregnant and postpartum women. ${ }^{6} 1214$

The question about the need for a higher threshold for sacroiliitis on MRI arises. Particularly the incorporation of structural lesions in the MRI definitions could augment the specificity.

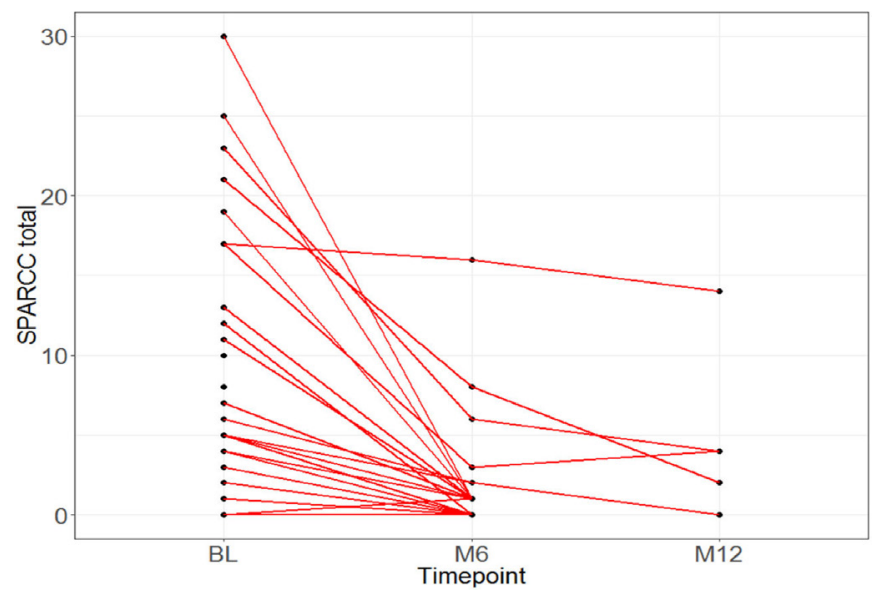

Figure 1 Evolution of the Spondyloarthritis Research Consortium of Canada (SPARCC) scores over time. Each dot represents an MRI of the sacroiliac joints. MRI examinations of the same subject are connected by a straight line. BL, baseline MRI; M6, month 6 MRI; M12, month 12 MRI.
Active lesions remain the hallmark for assessment of inflammation in sacroiliitis, but structural lesions increasingly play a role in SpA diagnosis. ${ }^{27}$ In the present study, few postpartum women demonstrated structural lesions on MRI-SIJ, which endorses this assumption. The lack of development of fat metaplasia could indicate towards a more mechanical, compared with inflammatory origin of the BMO lesions. ${ }^{14}$ However, the follow-up period may not be long enough to detect this transformation. The lack of structural lesions in our study population is in concordance with the existing literature. Intermediate to high levels of erosions appear to offer a high level of specificity for axSpA. ${ }^{26}$ Weber et al suggested that incorporating erosions in the ASAS MRI definitions would enhance sensitivity from 67\% to $81 \%$ while maintaining specificity. ${ }^{28}$ De Winter et al concluded that deep BMO lesions are almost exclusively found in patients with axSpA. ${ }^{6}$ A recent retrospective, cross-sectional study of pelvic MRI in a large population of individuals without a rheumatologic condition found that erosions were uncommon and had no age-dependent increase. ${ }^{29}$ In another study, no structural changes on MRI were found in pregnant or postpartum women. ${ }^{14}$ In the aforementioned study by Seven et al, erosions were only present in patients with axSpA and women with postpartum pain, however, with significantly higher prevalence and severity

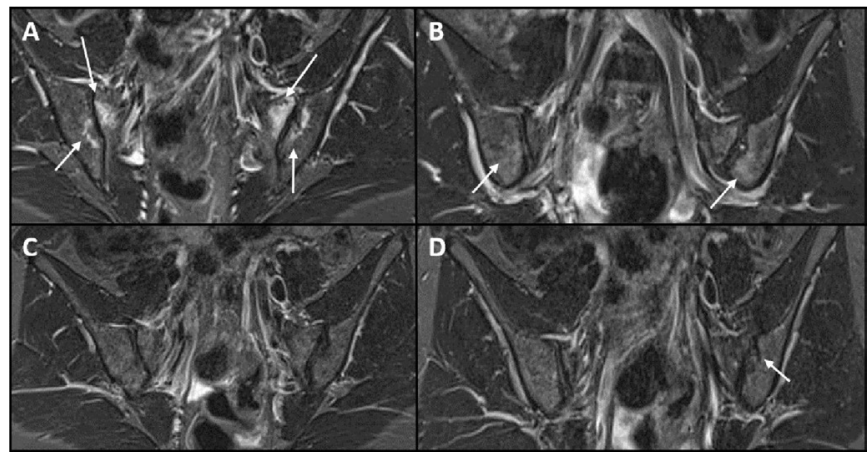

Figure 2 Sacroiliac joint MRI examinations of a 31-year-old postpartum woman. (A) Extensive sacroiliac bone marrow oedema (BMO) on shorttau inversion recovery images at baseline; (B) decrease of the BMO after 6 months; $(C)$ vanishing of the BMO after 12 months; (D) T1 sequences of the month 12 MRI showing sacroiliac erosions. 
Table 3 Correlation of baseline SPARCC scores and the presence of sacroiliitis on baseline MRI with clinical data

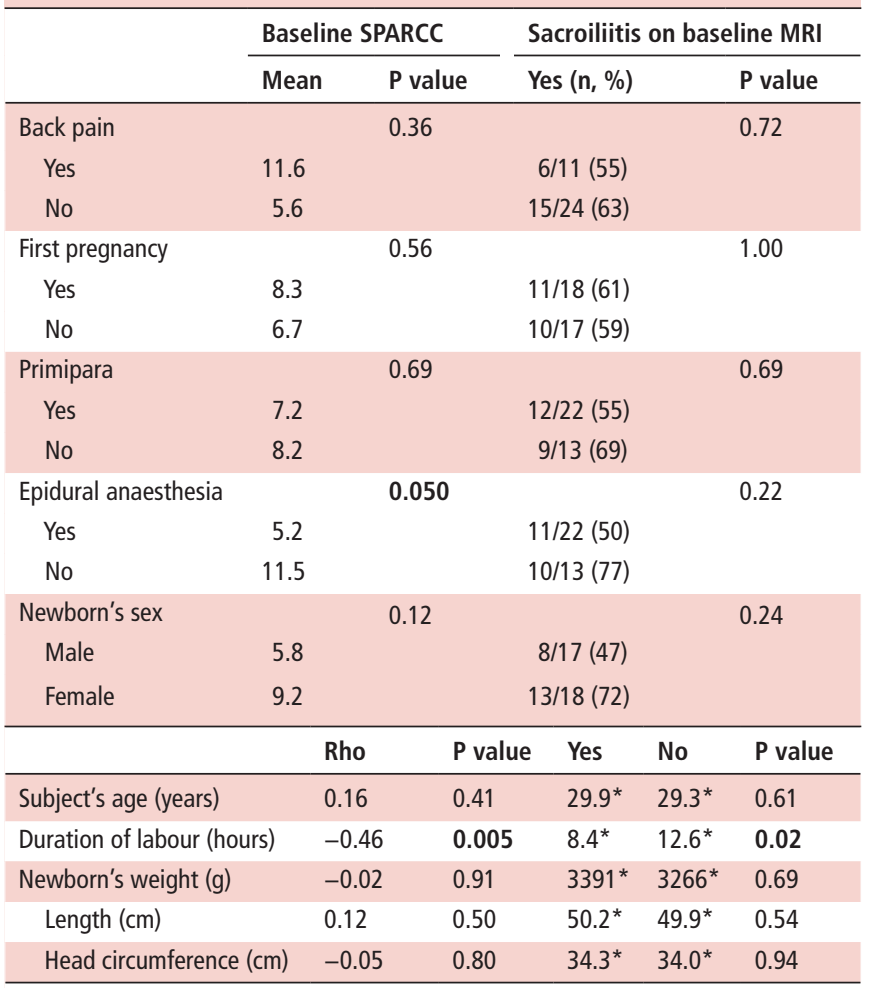

Significant correlations are shown in bold.

${ }^{*}$ Mean values.

SPARCC, Spondyloarthritis Research Consortium of Canada.

in the first. Ankylosis and backfill were only seen in patients with axSpA, making these features highly specific. ${ }^{26}$

As back pain is common in postpartum women, ${ }^{17} 3031$ the differential diagnosis with axSpA is a factual issue in clinical practice. In contrast to the pre-MRI era, in which underdiagnosis of SpA was common, nowadays the risk of overdiagnosis is apparent. This holds several pitfalls. Back pain patients with a false diagnosis of axSpA will likely have less therapeutic effect of non-steroidal anti-inflammatory drugs and are subsequently more likely to receive ineffective biological therapy, which has significant potential side effects and encompasses high socioeconomic costs. Unnecessarily, those patients suffer from the psychological consequences of dealing with a chronic, incurable condition. Considering the significant drop in BMO over time in our study, it seems advisable to wait at least 6 months to perform an MRI-SIJ in postpartum women presenting with back pain. When the MRI is considered as suggestive of SpA, it should be repeated more than 1 year after giving birth.

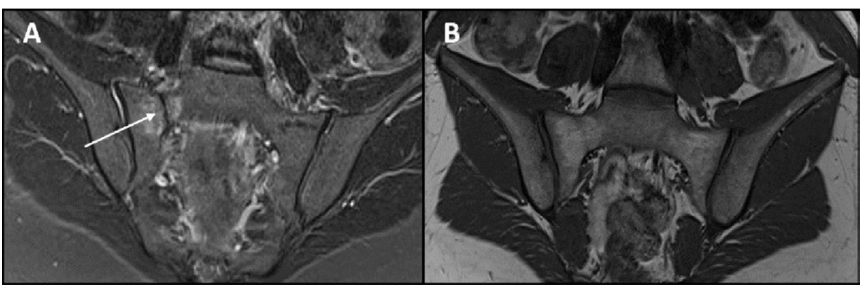

Figure 3 A postpartum sacral fracture on sacroiliac joint MRI of a 28-year-old woman. (A) Shorttau inversion recovery (STIR) sequences of the baseline MRI show a clear fracture of the sacral bone. (B) STIR sequences show a healed sacral fracture after 6 months.
Interestingly, the presence of sacroiliac BMO was associated with a shorter duration of labour. At first sight, this could appear counterintuitive. However, a shorter labour likely reflects an association with more biomechanical stress in a shorter time period. SPARCC scores were significantly lower in subjects undergoing epidural anaesthesia. A more painful labour may be associated with higher levels of biomechanical stress due to an inefficient labour. Both correlations indicate towards a more important role of giving birth compared with the pregnancy itself in the occurrence of BMO on MRI-SIJ. Nevertheless, Eshed et al showed a high frequency of sacroiliac BMO, both prepartum and postpartum. ${ }^{14}$ In a study by Agten et al, no differences in BMO between women with and without caesarean section were found. ${ }^{12}$ The dual relationship between biomechanical stressinduced MRI lesions mimicking sacroiliitis and the role of biomechanical stress in the pathophysiology of SpA complicates the interpretation of MRI-SIJ in postpartum women with back pain even further. ${ }^{32} 33$

In $60 \%$ of the subjects, other aberrant MRI findings were reported. Symphysis pubis BMO was seen in a significant portion of postpartum women. Although this is generally not regarded as an SpA lesion, a study by Jans et al found a high specificity of symphysis pubis BMO on MRI in patients with axial SpA at time of diagnosis. ${ }^{34}$ Sacral fracture is considered to be a rare complication of giving birth. ${ }^{35}$ Nonetheless, in this rather small study population, MRI detected two sacral fractures. The fractures were asymptomatic and giving birth was atraumatic and without complications, making these findings accidental. Thus, presumably, the prevalence of postpartum sacral fractures is higher than previously thought.

Major strengths of the present study are the prospective acquisition of postpartum women who would not have been symptomatic enough to warrant further investigation, the correlation with clinical data from mother and child, and the repeated MRI examinations, allowing evaluation of the evolution of the lesions. Other strengths include the blinded reads by three independent, experienced and calibrated readers. Limitations are the small sample size and the exclusion of postpartum women who gave birth through caesarean section to better investigate the role of pregnancy versus childbirth in the occurrence of sacroiliac MRI lesions. Considering the small study population, a multivariate analysis is not reliable and therefore not added to this manuscript.

In conclusion, women immediately postpartum show a markedly high prevalence of sacroiliac BMO on MRI. A significant proportion of the women even fulfilled the ASAS definition of a positive MRI for sacroiliitis, which questions the threshold of this definition. These MRI findings decrease over time, even though a fraction retains $\mathrm{BMO}$ over 1 year. When suspecting axSpA, our data indicate the need to wait at least 6 months to perform an MRI-SIJ in postpartum women, and, if positive, repeat the MRI after 12 months. Our data also underscore that interpretation of MRI in the appropriate clinical context is extremely important.

\section{Twitter Philippe Carron @PhilippeCarron}

Acknowledgements We thank the study subjects and the staff of the Department of Obstetrics of the Ghent University Hospital for their help in conducting this study.

Contributors $T R$ and $A D$ contributed equally to this manuscript and share first authorship. FEVdB and DE both supervised the manuscript and act as senior author. TR, AD, GV, FEVdB and DE conceived of the presented idea. ID, GV and $K R$ helped in recruiting the subjects. TR, AD, A-SDC, LD, GV and PC recruited the subjects and collected the study data. LJ, MdH and NH evaluated and scored the magnetic resonance images. A-SDC did the statistical analyses. TR and AD wrote the manuscript. FVdB and DE reviewed the manuscript. 
Funding This observational prospective study has been supported by an Assessment of SpondyloArthritis International Society (ASAS) research grant. DE is supported by grants of the Fund for Scientific Research-Flanders (FWO), an Excellence of Science Grant (EOS), Fund for Scientific Rheumatology Research (FWRO) and the Research Council of Ghent University.

Competing interests None declared.

Patient and public involvement Patients and/or the public were not involved in the design, or conduct, or reporting or dissemination plans of this research.

Patient consent for publication Not required.

Ethics approval This study was approved by the Ethics Committee of the Ghent University Hospital. All study subjects provided written informed consent.

Provenance and peer review Not commissioned; externally peer reviewed.

Data availability statement Data are available on reasonable request.

\section{ORCID iDs}

Thomas Renson http://orcid.org/0000-0002-5503-000X

Manouk de Hooge http://orcid.org/0000-0002-0652-9808

Philippe Carron http://orcid.org/0000-0001-9254-6171

Dirk Elewaut http://orcid.org/0000-0002-7468-974X

\section{REFERENCES}

1 Rudwaleit M, Jurik AG, Hermann K-GA, et al. Defining active sacroiliitis on magnetic resonance imaging (MRI) for classification of axial spondyloarthritis: a consensual approach by the ASAS/OMERACT MRI group. Ann Rheum Dis 2009;68:1520-7.

2 Rudwaleit M, van der Heijde $D$, Landewé $R$, et al. The development of assessment of spondyloarthritis International Society classification criteria for axial spondyloarthritis (Part II): validation and final selection. Ann Rheum Dis 2009:68:777-83.

3 Weber U, Østergaard M, Lambert RGW, et al. Candidate lesion-based criteria for defining a positive sacroiliac joint MRI in two cohorts of patients with axial spondyloarthritis. Ann Rheum Dis 2015;74:1976-82.

4 Weber $U$, Jurik $A G$, Zejden $A$, et al. Frequency and anatomic distribution of magnetic resonance imaging features in the sacroiliac joints of young athletes: exploring "background noise" toward a data-driven definition of sacroiliitis in early spondyloarthritis. Arthritis Rheumatol 2018;70:736-45.

5 Varkas G, de Hooge M, Renson T, et al. Effect of mechanical stress on magnetic resonance imaging of the sacroiliac joints: assessment of military recruits by magnetic resonance imaging study. Rheumatology 2018;57:508-13.

6 de Winter J, de Hooge M, van de Sande M, et al. Magnetic resonance imaging of the sacroiliac joints indicating sacroiliitis according to the assessment of spondyloarthritis International Society definition in healthy individuals, runners, and women with postpartum back pain. Arthritis Rheumatol 2018;70:1042-8.

7 Molto A, Gossec L, Lefèvre-Colau M-M, et al. Evaluation of the performances of 'typical' imaging abnormalities of axial spondyloarthritis: results of the cross-sectional ILOS-DESIR study. RMD Open 2019;5:e000918.

8 Lambert RGW, Bakker PAC, van der Heijde D, et al. Defining active sacroiliitis on MRI for classification of axial spondyloarthritis: update by the ASAS MRI Working group. Ann Rheum Dis 2016:75:1958-63.

9 Baumberger H, Khan M. SAT0417 Gradual progressive change to equal prevalence of ankylosing spondylitis among males and females in switzerland: data from the swiss ankylosing spondylitis society (SVMB) [abstract]. Ann Rheum Dis 2017;76:929.

10 Calin A, Elswood J, Rigg S, et al. Ankylosing spondylitis--an analytical review of 1500 patients: the changing pattern of disease. J Rheumatol 1988;15:1234-8.

11 Will R, Edmunds L, Elswood J, et al. Is there sexual inequality in ankylosing spondylitis? A study of 498 women and 1202 men. J Rheumatol 1990;17:1649-52.

12 Agten CA, Zubler V, Zanetti M, et al. Postpartum bone marrow edema at the sacroiliac joints may mimic sacroiliitis of axial spondyloarthritis on MRI. AJR Am J Roentgenol 2018;211:1306-12.

13 Bjelland EK, Eberhard-Gran M, Nielsen CS, et al. Age at menarche and pelvic girdle syndrome in pregnancy: a population study of 74973 women. BJOG 2011;118:1646-52.

14 Eshed I, Miloh-Raz H, Dulitzki M, et al. Peripartum changes of the sacroiliac joints on MRI: increasing mechanical load correlating with signs of edema and inflammation kindling spondyloarthropathy in the genetically prone. Clin Rheumatol 2015:34:1419-26.

15 Fast A, Shapiro D, Ducommun EJ, et al. Low-Back pain in pregnancy. Spine 1987;12:368-71.

16 Verstraete EH, Vanderstraeten G, Parewijck W. Pelvic girdle pain during or after pregnancy: a review of recent evidence and a clinical care path proposal. Facts Views Vis Obgyn 2013;5:33-43.

17 Larsen EC, Wilken-Jensen C, Hansen A, et al. [Pregnancy associated pelvic pain. I: Prevalence and risk factors]. Ugeskr Laeger 2000;162:4808-12.

18 Maksymowych WP, Inman RD, Salonen D, et al. Spondyloarthritis research Consortium of Canada magnetic resonance imaging index for assessment of sacroiliac joint inflammation in ankylosing spondylitis. Arthritis Rheum 2005;53:703-9.

19 de Hooge M, van den Berg R, Navarro-Compán V, et al. Patients with chronic back pain of short duration from the space cohort: which MRI structural lesions in the sacroiliac joints and inflammatory and structural lesions in the spine are most specific for axial spondyloarthritis? Ann Rheum Dis 2016;75:1308-14.

20 Harris PA, Taylor R, Minor BL, et al. The REDCap Consortium: building an international community of software platform partners. J Biomed Inform 2019;95:103208.

21 Harris PA, Taylor R, Thielke R, et al. Research electronic data capture (REDCap)--a metadata-driven methodology and workflow process for providing translational research informatics support. J Biomed Inform 2009;42:377-81.

22 Thein R, Burstein G, Shabshin N. Labor-related sacral stress fracture presenting as lower limb radicular pain. Orthopedics 2009;32:447-50.

23 Baraliakos X, Thomaschoff J, Fruth M, et al. OP0032 Localization and morphology of magnetic resonance imaging features of pathologic changes in the sacroiliac joints suggestive of axial spondyloarthritis - a systematic comparison of patients and controls with chronic back pain [abstract]. Ann Rheum Dis 2019;78:85.

24 van der Heijde D, Sieper J, Maksymowych WP, et al. Clinical and MRI remission in patients with nonradiographic axial spondyloarthritis who received long-term openlabel adalimumab treatment: 3-year results of the ABILITY-1 trial. Arthritis Res Ther 2018;20:61.

25 Varkas G, Jans L, Cypers H, et al. Brief report: six-week treatment of axial spondyloarthritis patients with an optimal dose of nonsteroidal antiinflammatory drugs: early response to treatment in signal intensity on magnetic resonance imaging of the sacroiliac joints. Arthritis Rheumatol 2016:68:672-8.

26 Seven S, Østergaard M, Morsel-Carlsen L, et al. MRI lesions in the sacroiliac joints for differentiation of patients with axial spondyloarthritis from postpartum women, patients with disc herniation, cleaning staff, long distance runners and healthy persons - a prospective cross-sectional study of 204 participants. Arthritis Rheumatol 2019;71:2034-46

27 Jans L, Egund N, Eshed I, et al. Sacroiliitis in axial spondyloarthritis: assessing morphology and activity. Semin Musculoskelet Radiol 2018;22:180-8.

28 Weber U, Lambert RGW, Østergaard M, et al. The diagnostic utility of magnetic resonance imaging in spondylarthritis: an international multicenter evaluation of one hundred eighty-seven subjects. Arthritis Rheum 2010;62:3048-58.

29 Ziegeler K, Eshkal H, Schorr C, et al. Age- and sex-dependent frequency of fat metaplasia and other structural changes of the sacroiliac joints in patients without axial spondyloarthritis: a retrospective, cross-sectional MRI study. J Rheumatol 2018:45:915-21.

30 Albert HB, Godskesen M, Korsholm L, et al. Risk factors in developing pregnancyrelated pelvic girdle pain. Acta Obstet Gynecol Scand 2006;85:539-44.

31 Ostgaard HC, Zetherström G, Roos-Hansson E. Back pain in relation to pregnancy: a 6-year follow-up. Spine 1997;22:2945-50.

32 McGonagle D, Wakefield RJ, Tan AL, et al. Distinct topography of erosion and new bone formation in Achilles tendon enthesitis: implications for understanding the link between inflammation and bone formation in spondylarthritis. Arthritis Rheum 2008;58:2694-9.

33 Jacques $\mathrm{P}$, Lambrecht S, Verheugen $\mathrm{E}$, et al. Proof of concept: enthesitis and new bone formation in spondyloarthritis are driven by mechanical strain and stromal cells. Ann Rheum Dis 2014;73:437-45.

34 Jans L, van Langenhove C, Van Praet L, et al. Diagnostic value of pelvic enthesitis on MRI of the sacroiliac joints in spondyloarthritis. Eur Radiol 2014;24:866-71.

35 Malherbe JJ, Davel S. An atraumatic sacral fracture with lumbosacral radiculopathy complicating the early postpartum period: a case report. Am J Case Rep 2019;20:794-9. 


\section{Correction: High prevalence of spondyloarthritis-like MRI lesions in postpartum women: a prospective analysis in relation to maternal, child and birth characteristics}

Renson T, Depicker A, De Craemer A-S, et al. High prevalence of spondyloarthritis-like MRI lesions in postpartum women: a prospective analysis in relation to maternal, child and birth characteristics. Ann of Rheum Dis 2020;79:929-34.

There is a mislabeling of MRI sequences within the figures. The figures have been amended:

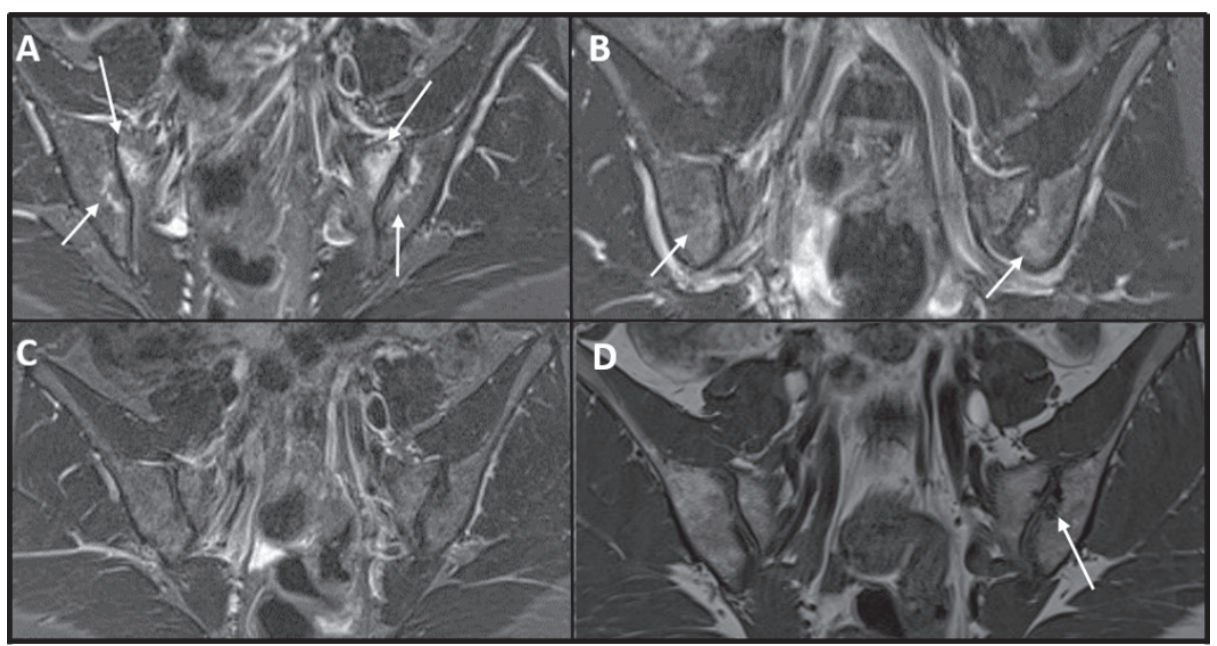

Figure 2 Sacroiliac joint MRI examinations of a 31 year-old postpartum woman. A: extensive sacroiliac bone marrow oedema on stir images at baseline; $B$ : decrease of the bone marrow oedema after 6 months; C: vanishing of the bone marrow oedema after 12 months; D: T1 sequences of the month 12 MRI showing sacroiliac erosions.

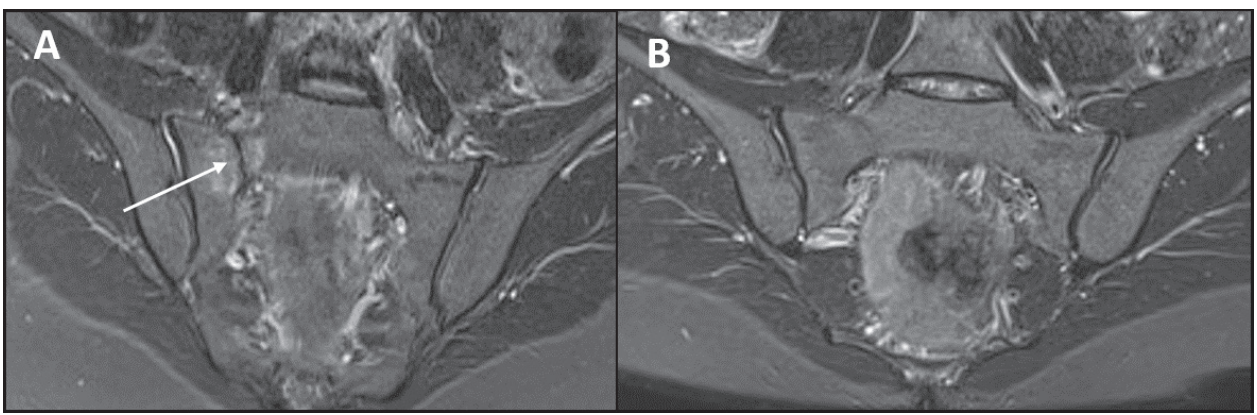

Figure 3 A postpartum sacral fracture on sacroiliac joint MRI of a 28 year-old woman. A: stir sequences of the baseline MRI show a clear fracture of the sacral bone; B: stir sequences show a healed sacral fracture after 6 months. 


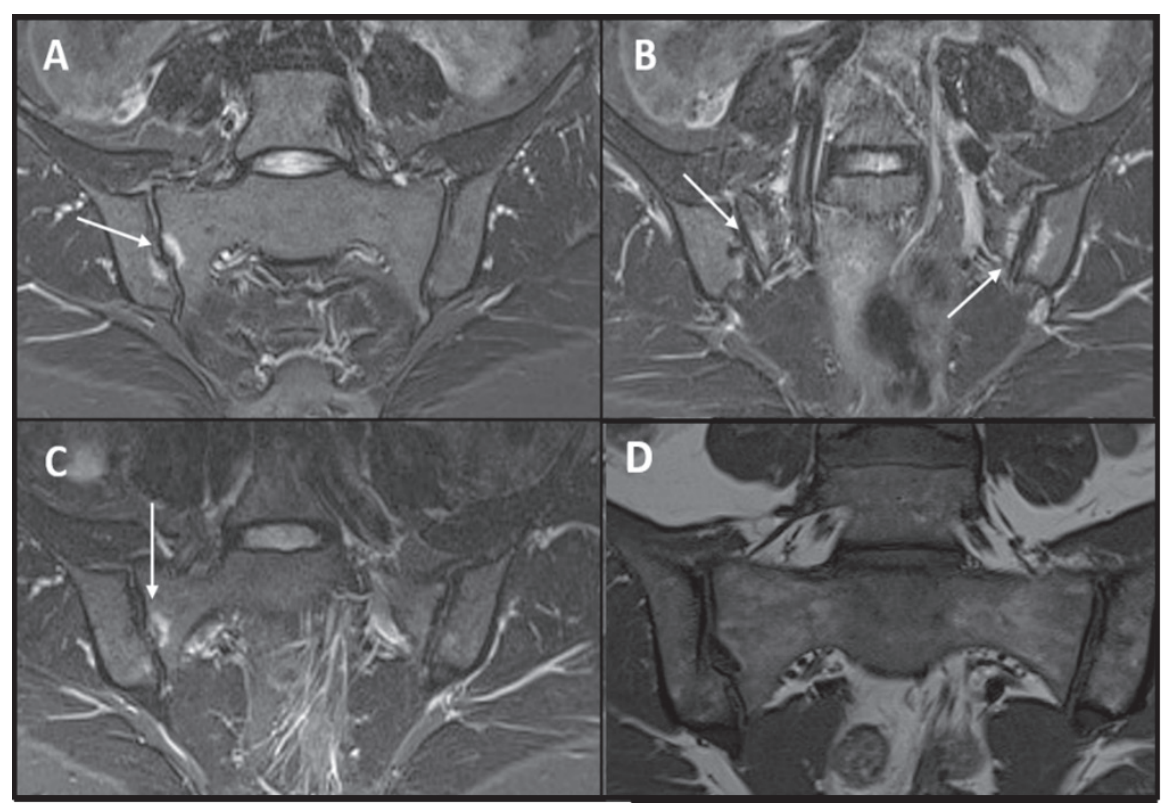

Figure S3 Postpartum sacroiliac MRI images of a 32 year-old woman. A and B: intense sacroiliac bone marrow edema on stir sequences immediately after giving birth; $C$ : decrease of the sacroiliac bone marrow edema on the month 6 MRI stir sequences; D: no structural lesions on the month 12 MRI T1 images. doi:10.1136/annrheumdis-2020-217095.

(C) Author(s) (or their employer(s)) 2021. No commercial re-use. See rights and permissions. Published by BMJ. Ann Rheum Dis 2021;80:e28. doi:10.1136/annrheumdis-2020-217095corr1

(D) Check for updates 